\title{
RESEARCH AND INNOVATION STRATEGIC ALLIANCE OF CEDARS-SINAI MEDICAL CENTER AND CENTRAL - EASTERN EUROPEAN (CEE) ACADEMIC ORGANIZATIONS
}

\author{
*Sandor G. Vari \\ MD, International Research and Technology Transfer Manager, Burns and Allen Research Institute, \\ Department of Academic Affairs, Cedars-Sinai Medical Center
}

* James D. Laur

J.D., Deputy General Counsel, Department of Legal Affairs, Cedars-Sinai Medical Center

${ }^{*}$ Dr. Sandor G. Vari received his medical doctor degree in 1978, Budapest, Hungary and he completed his surgical residency from 1978 to 1983 at the 1st Department of Surgery. From 1985 through 1990 he held the position of assistant professor of surgery at Semmelweis Medical University Budapest. In 1988, he received a fellowship from Brig Research Ltd., and in 1989 he was awarded a Fulbright scholarship to study biomedical photonics at Cedars-Sinai Medical Center. After his research works in 2000 he became the International Research and Technology Transfer Manager at Cedars-Sinai Medical Center Burns \& Allen Research Institute. In the same year he started the development of the "Innovation Management and Technology Transfer Training" (IMTT) Program to assist Central and Eastern European Countries in the implementation of institutional policies and procedures. In 2004 he commenced the "Research and Innovation Management Training" (RIMETTM) Program to train scientists, physicians and healthcare managers in Central - Eastern European Countries. In 2005 he conceived the concept of the "Intellectual Property Warehouse TM" (IPWTM), a joint patent portfolio management strategy for the Central and Eastern European partners. E-mail: sandor.vari@cshs.org

**Short resume of James D. Laur, J.D is available in the article: Patent Warehouse: Strategic Alliances for Commercialization of Intellectual Property in Central \& East Europe.

\begin{abstract}
In 2000 Cedars-Sinai Medical Center (CSMC) has developed the "Innovation Management and Technology Transfer Training" (IMTT) Program and in 2004 the "Research and Innovation Management Training" (RIMET) Program to train scientists, physicians and healthcare managers at CSMC and in Central - Eastern European (CEE) Countries in research and technology transfer management. CSMC believes that it is essential for its partner universities to have the ability to protect the intellectual advances that arise from their laboratories and to negotiate commercially appropriate licensing deals. The IMTTTM and RIMETTM programs educate and train managers in research, innovation management, business development, and licensing to build a robust intellectual property portfolio and incorporate the institutional patent portfolios into a "Joint Patent Portfolio" (JPP) to connect academic organizations throughout CEE in an "Intellectual Property WarehouseTM" (IPWTM).
\end{abstract}




\section{BACKGROUND}

Innovation emerges from the interplay of universities, national laboratories, and industrial firms in an environment shaped by a growing body of governmental rules and incentives [1] .

Advances in the fundamental sciences underlying health, such as biology, behavioral sciences, and physics, are critical to the development of new diagnostic and therapeutic technologies. Over the past 50 years, for example, about $50 \%$ of Nobel Prizes in Medicine or Physiology were awarded to researchers who discovered the structure and function of DNA and 7 Nobel Prizes in Chemistry were awarded to related work [2] . Most of this work, though academic in origin, has had substantive industrial implications. The revolution in genetics and molecular biology spawned the biotechnology industry [3, 4], which have from its inception been intimately tied, to academic scientists. The industry's tendency to locate close to research universities acknowledges the value of star academic scientists in biotechnology $[5,6]$. Today, academic scientists continue to serve 3 key functions in the biotechnology industry: they facilitate knowledge transfer, signal the quality of the indistries' research to capital markets, and help chart the scientific direction of the industry [7].

Responding to the political and economic shifts in the Central and Eastern European (CEE) Countries toward a free market economy, major universities have begun to create research management and technology transfer offices to facilitate the patent and licensing processes. In addition, emerging high-tech and biotechnology companies can struggle to survive because they often possess characteristics that are more similar to academic laboratories and, unlike large corporations, do not possess the capital or resources necessary to achieve targeted product development. Technology assessment is seen as a mechanism for achieving effec- tive and efficient use of resources; yet, institutions have not fully utilized or implemented a technology transfer program to maximize the economic potential of their technologies. Academic institutions can encounter considerable political, economic, and bureaucratic barriers when they attempt to develop and implement technology transfer offices and protocols [8].

\section{PRESENT STATE}

Medical Center is a nonprofit, tax-exempt academic medical center committed to expanding the horizons of medical knowledge and improving the quality of care to its patients. CedarsSinai has four charitable missions: the provision of healthcare, community service, medical education and biomedical research. Since its predecessor hospital was founded in Los Angeles, California, in 1902, Cedars-Sinai has grown to become the largest voluntary hospital west of the Mississippi and continues its traditional focus on providing the finest healthcare possible. During the course of its one hundred year history, many advances in all areas of healthcare have been made and hundreds of thousands of lives have been significantly impacted. More than 1,800 physicians in virtually all-medical specialties are on the Medical Staff at CedarsSinai. They join more than 8,000 employees, 2,000 volunteers and 15,000 fundraising support group members to form a unique partnership in delivering world-class medicine. CedarsSinai physicians are leaders in basic and clinical research, bringing advancements in medicine directly from the laboratory to the bedside. In addition, they teach over 245 residents and fellows in nearly 60 graduate medical education programs at Cedars-Sinai. The Technology Transfer Office at Cedars-Sinai manages an intellectual property portfolio of over 150 patents worldwide and received approximately $\$ 14$ million in royalty income from its licensing program in fiscal year 2005 . 


\section{Special Issue}

Cedars-Sinai Medical Center is an academic center committed to expanding the horizons of medical knowledge through biomedical research. Through its charitable missions, the Medical Center is committed to bringing the discoveries made in its research laboratories to the market so that the public can benefit from the scientific advances made by our faculty. Through research collaborations with Central and Eastern European Academic Organizations the Medical Center became aware of a distinct vacuum of knowledge and understanding of research and innovation management policies and intellectual property. Due to this lack of knowledge, this region has not been able to take full advantage of the benefits of the intellectual property wealth that can be found in its laboratories.

Cedars-Sinai developed an Innovation Management and Technology Transfer Training Program (IMTT) in response to requests from collaborating institutions in the CEE for assistance with the development of institutional policies and procedures to enable them to manage their intellectual assets in an efficient and effective manner. Initially, the program was originally developed with four medical universities in Hungary and was structured as a part of Cedars-Sinai's charitable mission of education. The basic concept was that given that research has no borders, Cedars-Sinai had an obligation to share its best practices in technology transfer with its sister academic institutions in the CEE.

In autumn of 2003, the Medical Center, along with the Fogarty International Center at the National Institutes of Health, hosted the "Bridges in Life Sciences" symposium, presenting topics such as grantsmanship, innovation management and research collaborations to participants from over ten countries.

At present, the Bridges in Life Sciences meeting concept has been presented all over CEE in academic and research institutions from Poland to Romania with great success, in an attempt to fulfill the Medical Center's charita- ble and educational mission and emphasize the notion that research has no borders.

From 2000 the Medical Center is implementing an Innovation Management and Technology Transfer Training Program ("IMTT Training Program") for academic institutions in the Czech Republic, Hungary, Poland, Romania and the Slovak Republic. In 2005, the Medical Center extended its program and foster a relationship with institutions in Bulgaria and Ukraine. Our IMTT Training Program has three different stages:

\section{- INTRODUCE \\ - INVOLVE \\ - IMPLEMENT}

Each stage anticipates various levels of education and training activities for the partner university.

The universities in the CEE do not need to build intellectual prowess because that is already there. What the institutions need to do is recognize the intellectual property that is leaking from its laboratories and capture the value so that the moneys earned from licensing the innovations can be invested back into the laboratories.

The first step in the IMTT Training Program INTRODUCES the basic structure and key elements of Innovation Management and Technology Transfer functions to partner universities and provides the university faculties and administrations with an overview of Cedars-Sinai's past experiences in technology management.

During the INVOLVE stage an on-site evaluation is taking place at each partner and the Medical Center through its expertise and knowledge can help academic institutions understand how to assess IP and utilize the institution's strengths in specific research areas. The Medical Center also provides knowledge how to take advantage of market opportunities 


\section{Technologies, innovation management and technology transfer}

for the technologies owned by the CEE partners. CSMC's recommended key components of an effective IP management strategy are the IP survey, the investment strategy, the deployment strategy and the continuous maintenance and monitoring system for effective development of the IP strategy over time ("SWOT analysis").

In the IMPLEMENT stage the Medical Center provides a comprehensive in-house education and training program "Research and Innovation Management Training" (RIMETTM) to train scientists, physicians and healthcare managers at CSMC and in the Central - Eastern European Countries. The principal objective of the RIMET Program is to help in the development of solid research and technology management policies, human subject and clinical trial management.

In the last 15 years CSMC learned the intellectual property rights in upstream biomedical research belong to a large, diverse group of owners in the public and private sectors with divergent institutional agendas. Sometimes heterogeneity of interests can facilitate mutually agreeable allocations ("you take the credit, I'll take the money") [9] but in this setting, there are reasons to fear that owners will have conflicting agendas that make it difficult to reach agreement. When owners have conflicting goals and each can deploy its rights to block the strategies of the others, they may not be able to reach an agreement that leaves enough private value for downstream developers to bring products to the market. A more subtle conflict in agendas arises between owners that pursue endproduct development and those that focus primarily on upstream research [10].

A proliferation of patents on individual fragments held by different owners seems inevitably to require costly future transactions to bundle licenses together before a industry can have an effective right to develop these products [11] .
Those are the main reasons CSMC and the CEE partners decided to build a Joint Patent Portfolio or "Intellectual Property WarehouseTM" (IPW) on this way the collaborative assessment of "patents of interest" can help guide formulate an effective marketing strategy. Once the "IPWTM" assembles its collection of portfolio patents, CSMC and the CEE Universities will work together to identify valuable patents, potential licensees and CSMC will be responsible for the effective portfolio management.

\section{RESULTS}

The CEE Universities understood that the establishment of a competent and effective technology transfer program is a long process. It can take a minimum of three to five years for a university to achieve the basic goals outlined in the three different stages of the IMTT Training Program and establish a functional and productive technology transfer program. For this reason, Cedars-Sinai has decided that it is essential to make its technology transfer infrastructure and expertise available to Partner Universities during this transition period. By working together under a Technology Collaboration Letter Agreement, Cedars-Sinai can provide universities with the opportunity to take advantage of Cedars-Sinai's existing technology transfer office's expertise and experiences. If the university has a technology which is potentially valuable and would like Cedars-Sinai's assistance, Cedars-Sinai can help the partner university learn how CSMC assesses, protects and commercializes intellectual property by actually observing how Cedars-Sinai approaches the innovation management process. More importantly, if the licensing effort for the technology selected by the university is successful, then the university will generate income for its program during the transition time that is required before a technology transfer program to be fully 


\section{Special Issue}

established. Any net royalty income from the licensed technologies will then go back to the Partner University to provide additional research monies and to help finance the Technology Transfer Office and its infrastructure at the university.

During the last 15 years, many companies have approached CSMC to search its patent portfolio and licensed several of them. Over that same period, CSMC has become successful in identifying innovations that have the greatest potential to generate revenue. As a Broker, CSMC has the expertise to assess the economic value of patents and to identify target companies, products, and potential licensees for future licensing efforts.

The broad scope of the Joint Patent Portfolio will reflect the diversity of world-class research projects carried out at the CEE Partner Universities. The fundamental features of a Joint Patent Portfolio initiated by CSMC include the integration of complementary technologies, the reduction of transaction costs, the resolution of conflicting patent positions and the avoidance of costly patent infringement litigation. Its effectiveness springs principally from a consensus among the participants that individual patent rights will remain at the owner organization and will be made available to other members on fair, reasonable and nondiscriminatory terms.

Management of the Joint Patent Portfolio involves a collaborative effort from outside patent lawyers, business development/licensing firms, intellectual property and financial organizations and investors. Typical management duties involve monitoring patent activity in a specific technology area, or keeping updated on competitors' patents. Consistent and continuous management of the Joint Patent Portfolio ensures that the participating CEE academic organizations remain competitive in both research development and licensing opportunities.
- The IPWTM would include patents on a variety of materials and methods that play important roles in biotechnology.

- $\quad$ The IPWTM would charge a fee for access to the collection of portfolios; this way, pharmaceutical and other healthcare companies could examine and express their interest in technologies within the Joint Patent Portfolio.

- The IPWTM would charge the market price for licensing services and reimburse patent holders for licensing activities.

- The IPWTM would also provide patent holders with a large share of the income from royalties generated from the Joint Patent Portfolio.

- The remainder of the royalty income will go to the maintenance of "Intellectual Property WarehouseTM" and will be shared with the Broker (CSMC).

The Central and Eastern European (CEE) Partner Universities who consider joining the Joint Patent Portfolio and the Patent Warehouse $^{\mathrm{TM}}$ must make a long-term commitment to the project.

\section{CONCLUSION}

The Central and Eastern European Academic Institutions must have a strong research and innovation management program and it is important for them to understand that for-profit companies will exploit and overwhelm academic institutions that are unprepared to protect and take control of the institution's innovations. In effect, there is more that a university and a professor can accomplish beyond the out- 


\section{Technologies, innovation management and technology transfer}

puts of their research merely publishing peerreview articles and increasing the individual's academic status based on impact factors and the citation index.

As an end result of the IMTT Program the goal of the CEE Universities beside to make available the outputs of their research also to implement infrastructure and protect the outcomes of their high quality scientific work. Hence CSMC's main goal is to help the CEE university administration and research community understand that they can bring more value to society by ensuring that the scientific outputs made at the university are brought to the market as outcomes like new drugs, medical devices, laboratory tests and treatment modalities and on this way they will make a better health care and healthier people in their countries. Those are the real socio-economic impacts of the innovative research work.

After the implementation of a transparent and effective IP strategy at the Central and Eastern European (CEE) Academic Organizations it will make them capable to incorporate the institutional patent portfolios into a "Joint Patent Portfolio" (JPP) and as an end result of CSMC efforts the partners will develop a commercially successful patent management strategy for the "Intellectual Property WarehouseTM" (IPWTM).

\section{REFERENCES}

1. Science and Engineering Indicators. Washington, DC: National Science Board; 2000.

2 B. Feldman. The Nobel Prize: A History of Genius, Controversy, and Prestige. New York, NY: Arcade Publishing Inc; 2000.

3. R. Henderson, L. Orsenigo, GP. Pisano. The pharmaceutical industry and the revolution in molecular biology. In: Mowery DC, Nelson RR, eds. Sources of Industrial Leadership: Studies of Seven Industries. Cambridge, Mass: Cambridge University Press; 1999: 267-311.

4. N. Rosenberg, RR. Nelson. American universities and technical advance in industry. Res Policy. 1994; 23: 323-348.

5. LG. Zucker, MR. Darby. Star scientists and institutional transformation. Proc Natl Acad Sci U S A. 1996; 93: 12709-12716.

6. LG. Zucker, MR. Darby, MB. Brewer. Intellectual human capital and the birth of US biotechnology enterprises. American Economic Rev. 1998; 88: 290-306.

7. DB. Audretsch, PA Stephan. Company-scientists locational links. American Economic Review. 1996; 86: 641-652.

8. SG Vari, JD Laur. Learning from Lost Opportunities \& Sharing Best Practices. Journal of the Association of University Technology Managers, 2005; Volume XVII Number 2 (accepted).

9. G. D. Libecap. Contracting for Property Rights (Cambridge Univ. Press, Cambridge, UK, 1989).

10. D. Fundenberg and E. Maskin. Econometrica 54, 533 (1986).

11. R. Merges and R. Nelson. Columbia Law Rev. 90, 839 (1990). 